\title{
Stochastic modelling of mortality and financial markets
}

\author{
Helena Aro* $\quad$ Teemu Pennanen ${ }^{\dagger}$
}

April 3, 2012

\begin{abstract}
The uncertain future development of mortality and financial markets affects every life insurer. In particular, the joint distribution of mortality and investment returns is crucial in determining capital requirements as well as in pricing and hedging of mortality-linked securities and other life insurance products. This paper proposes simple stochastic models that are well suited for numerical analysis of mortality-linked cash flows. The models are calibrated with a data set covering six countries and 56 years. Statistical analysis supports the known dependence of old-age mortality on GDP which, in turn, is connected to many sectors of financial markets. Our models allow for a simple quantitative description of such connections. Particular attention is paid to the long-term development of mortality rates, which is an important issue in life insurance.
\end{abstract}

Keywords: Mortality risk, market risk, stochastic modelling

\section{Introduction}

General mortality has fallen unexpectedly fast across all age groups over the past decades, with considerable fluctuations in the rate of improvement (Cairns et al., 2008). Pension providers and national security systems are incurring the costs of unpredictably improved longevity, as they need to pay out benefits longer than was anticipated. An ageing population and uncertainty in mortality improvements have created an acute need for efficient quantitative risk management methods for mortality-linked cash flows.

Various mortality-linked instruments have been proposed for hedging longevity risk. These include mortality bonds, mortality swaps and q-forwards whose cash-flows are linked to mortality developments in a specified population; see e.g. Blake and Burrows (2001); Blake et al. (2006a); Biffis and Blake (2009); Dowd et al. (2006); Lin and Cox (2005). It has been shown in (Cairns, 2011; Blake et al., 2006b; Li and Luo, To appear; Li and Hardy, 2011) how such instruments can be used to hedge mortality risk exposures in pension liabilities.

\footnotetext{
${ }^{*}$ Department of Mathematics and Systems Analysis, Aalto University, PL 1100, 02015 Aalto, Finland, haro@math.hut.fi

${ }^{\dagger}$ King's College London, Department of Mathematics, London WC2R 2LS, United Kingdom, teemu.pennanen@kcl.ac.uk
} 
There seems, indeed, to be strong demand for mortality-linked instruments but the supply side is less clear. The supply of mortality-linked instruments would likely increase if their cash-flows could be hedged by appropriate trading in more traditional assets for which liquid markets already exist. Such a development has been seen e.g. in options markets which boomed after the development of hedging strategies that could produce an option's cash-flows by appropriately trading the underlying asset; see (Scholes, 1998).

While the cash-flows of simple stock options are directly linked to traded assets, the cash-flows of mortality-linked instruments seem to have much less to do with existing financial markets. It follows that their cash flows cannot be perfectly hedged. In other words, the markets are incomplete and the seller of a mortality-linked instrument always retains some risk. Nevertheless, any connection between mortality and financial markets may help sellers to better adjust their investments to the cash-flows of the sold instruments and thus to reduce their mortality risk exposure. Such connections would be valuable also for pension or life insurers who seek to adjust their investment strategies so that their returns conform to the cash-flows of the insurance liabilities as well as possible.

This paper introduces simple stochastic models that allow for the incorporation of statistical links between mortality and financial markets. Using a data set covering six countries and 56 years, we look for consistent patterns in the long term development of mortality and financial markets. Based on the statistical analysis, we propose a model that incorporates the following features

- eventual stabilization of mortality rates,

- long-term link of old-age mortality to GDP,

- short-term connection between mortality and GDP,

- connection of GDP to interest rates.

While all these features may be questioned, there is both logical and statistical evidence in their favor.

Until now human mortality has generally decreased over time, but it is not clear how long mortality rates of different age groups will continue to diminish. It was conjectured already in Wicksell (1926) that, in the long run, mortality rates will tend to stabilize. Some experts suggest that lifestyle factors, such as obesity, may soon hinder further mortality improvements; see Olshansky et al. (2005). There is also some indication that the decline in coronary heart disease mortality is levelling out in some age groups in the UK and the Netherlands (Allender et al., 2008; Vaartjes et al., 2011). A recent survey of mortality trends in Europe can be found in Leon (2011).

There is evidence of a connection between mortality and economic cycles, usually represented by GDP or unemployment. Some studies suggest that in the long run, higher economic output results in lower mortality (Preston, 1975, 2007). The long-term connection between longevity risk and the economy is also discussed in Barrieu et al. (to appear). Others report a more immediate link between the phases of the economic cycle and mortality: Ruhm (2000) and Tapia Granados (2005a,b) discovered that mortality rates increase during economic expansions. The connection of GDP to both short-term and longterm mortality in six OECD-countries has recently been studied in Hanewald 
et al. (2011a) and Hanewald (2011b). They found that short-term mortality and macroeconomic fluctuations are closely linked, and on the other hand, the mortalities of various age groups display signs of cointegration with GDP.

GDP, in turn, is connected with various sectors of financial markets; see Stock and Watson (2003) for an extensive review. For example, there is strong evidence of a link between economic activity and the term spread of interest rates (Estrella and Mishkin, 1998; Haubrich and Dombrosky, 1996; Harvey, 1988, 1989; Estrella and Hardouvelis, 1991; Davis and Fagan, 1997; Plosser and Rouwenhorst, 1994), although the connection may have weakened since the mid-80s as suggested by Wheelock and Wohar (2009). Another connection exists between credit spreads (the difference between corporate and government bond yields) and GDP, as discussed e.g. in Friedman and Kuttner (1992), Bernanke (1990) and Duffie and Singleton (2003). Although the connection between stock markets and economic cycle is not unambiguous, there is evidence that such a link also exists (Mitchell and Burns, 1938; Fischer and Merton, 1985; Barro, 1990; Bosworth et al., 1975; Cole et al., 2008; Estrella and Mishkin, 1998). There is also some evidence of a direct link between demographic variables and financial markets, e.g. between population age structure and asset returns (Poterba, 2001; DellaVigna and Pollet, 2007).

While we have kept our model relatively simple, it also provides a convenient framework for describing more comprehensive connections between mortality and financial markets. Due to its present simple structure, the model is easy to study both analytically and numerically. This makes it well-suited for the analysis of mortality-linked cash-flows and associated investment strategies. The underlying risk factors in our model have natural interpretations, so its behaviour is easily judged by the user. It is easy to calibrate to both historical data and user's expectations about the future development of mortality and the economy. This is a useful feature, as historical data does not always provide the best description of expected future development of mortality.

The rest of this paper is organized as follows. Section 2 briefly recalls the mortality model introduced in Aro and Pennanen (2011) and fits the model to the historical data of six countries. Section 3 presents a statistical analysis of the risk factors. Based on the results of Section 3, Section 4 builds a stochastic model of the risk factors. Section 5 presents illustrative simulations.

\section{Parameterisation of mortality rates}

Stochastic mortality modelling has attracted steady attention in literature ever since the seminal work of Lee and Carter (1992); see e.g. Cairns et al. (2006, 2007); Renshaw and Haberman (2003); Brouhns et al. (2002); Lee and Miller (2001); Booth et al. (2002) and their references. Most of the proposed models describe age-dependent mortality rates by parametric functions of the age. Indeed, the age dependency displays certain regularities that can be used to reduce the dimensionality of a model. This idea was used already in the classical Gompertz model as well as in the stochastic model proposed in Aro and Pennanen (2011), which we now briefly recall.

Let $E_{x, t}$ be the number of individuals aged $[x, x+1)$ years at the beginning of year $t$ in a given population. The number of deaths $D_{x, t}$ among the $E_{x, t}$ 
individuals during year $[t, t+1)$ can be described by the binomial distribution:

$$
D_{x, t} \sim \operatorname{Bin}\left(E_{x, t}, q_{x, t}\right),
$$

where $q_{x, t}$ is the probability that an $x$ year-old individual randomly selected at the beginning of year $t$ dies during $[t, t+1)$. As in Aro and Pennanen (2011), we model the survival probabilites $p_{x, t}=1-q_{x, t}$ with the formula

$$
p_{x, t}=\frac{\exp \left(\sum_{i=1}^{n} v_{t}^{i} \phi^{i}(x)\right)}{1+\exp \left(\sum_{i=1}^{n} v_{t}^{i} \phi^{i}(x)\right)},
$$

where $\phi^{i}$ are user-defined basis functions and $v_{t}^{i}$ are stochastic risk factors that may vary over time. In other words, the yearly logistic survival probability of an $x$ year-old is given by

$$
\operatorname{logit} p_{x, t}:=\ln \left(\frac{p_{x, t}}{1-p_{x, t}}\right)=\sum_{i=1}^{n} v_{t}^{i} \phi^{i}(x) .
$$

The logistic transformation implies that the probabilities $p_{x, t}$ and $q_{x, t}=1-p_{x, t}$ remain in the interval $(0,1)$.

By an appropriate choice of the functions $\phi^{i}(x)$ one can incorporate certain desired features into the model. For example, the basis functions can be chosen so that the survival probabilities $p_{x, t}$ have a regular dependence on the age $x$ like, e.g. in the classical Gompertz model. As in Aro and Pennanen (2011), we will use the three piecewise linear basis functions given by

$$
\begin{aligned}
\phi^{1}(x) & = \begin{cases}1-\frac{x-18}{32} & \text { for } x \leq 50 \\
0 & \text { for } x \geq 50,\end{cases} \\
\phi^{2}(x) & = \begin{cases}\frac{1}{32}(x-18) & \text { for } x \leq 50 \\
2-\frac{x}{50} & \text { for } x \geq 50,\end{cases} \\
\phi^{3}(x) & = \begin{cases}0 & \text { for } x \leq 50 \\
\frac{x}{50}-1 & \text { for } x \geq 50 .\end{cases}
\end{aligned}
$$

The linear combination $\sum_{i=1}^{3} v_{t}^{i} \phi^{i}(x)$ will then be piecewise linear and continuous as a function of the age $x$; see Figure 1 . The risk factors $v_{t}^{i}$ now represent points on logistic survival probability curve:

$$
v_{t}^{1}=\operatorname{logit} p_{18, t}, v_{t}^{2}=\operatorname{logit} p_{50, t}, v_{t}^{3}=\operatorname{logit} p_{100, t} .
$$

It is to be noted that this is just one possible choice of basis functions. Another set of basis functions would result in another set of risk factors with different interpretations. In particular, the model of Cairns et al. (2006) corresponds to $\phi^{1}(x) \equiv 1$ and $\phi^{2}(x)=x-\bar{x}$, where $\bar{x}$ is the mean over all ages. In this case, the parameter $v^{1}$ describes the general level of mortality, while $v^{2}$ determines how mortality rates change with age. We will use the threeparameter model described above mainly because of its simple interpretation in the economic context. 


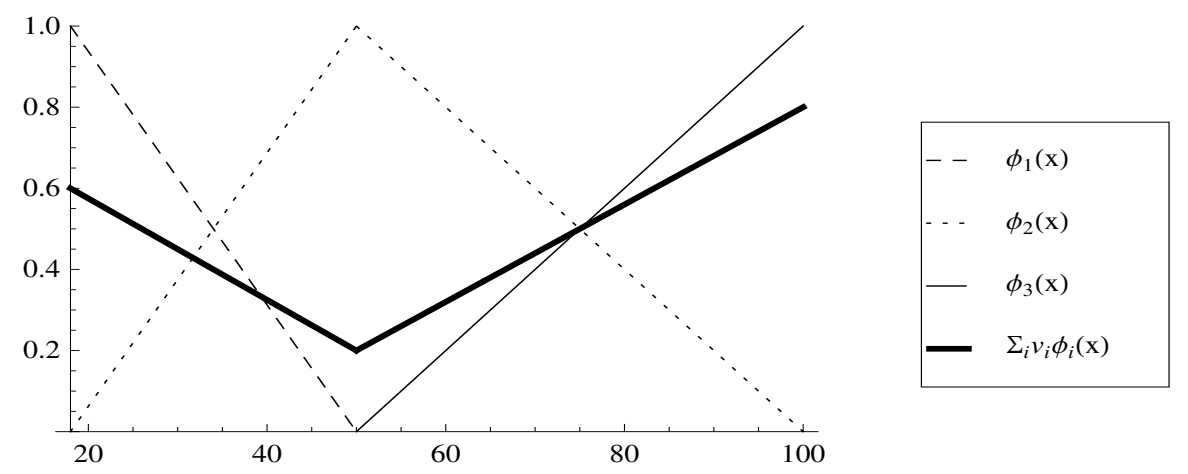

Figure 1: Three piecewise linear basis functions and their linear combination

Once the basis functions $\phi^{i}$ are fixed, the realized values of the corresponding risk factors $v_{t}^{i}$ can be easily calculated from historical data using standard maxlikelihood estimation. We fit equation (3) into the mortality data from six countries, obtained from the Human Mortality Database ${ }^{1}$. Plots of the historical values of the risk factors are presented in Figures 2, 3, 4, 5, 6 and 7 .

\section{Statistical analysis of the risk factors}

This section presents a statistical analysis of mortality and economic risk factors. In particular, we address the long-term development of the mortality risk factors, and study the connection of mortality with the economy. In order to get a comprehensive view of mortality dynamics in developed countries, we investigate the mortality dynamics of six large countries: Australia, Canada, France, Japan, the UK and the US. As one of our aims is to investigate whether mortality rates might level out in the future, we have chosen countries where life expectancy is already relatively high.

\subsection{Risk factor $v^{1}$}

The risk factor $v^{1}$ gives the annual logit survival probability of 18-year-olds. Overall, mortality of young adults is generally low in developed countries, and deaths are most commonly caused by accidents, assaults and suicide as reported by National Vital Statistics (2010). Such contributors may be unlikely to be efficiently eliminated by medical advances, regulatory interventions or lifestyle changes on a national level. There is also some evidence that the decline in coronary heart disease mortality is slowing down or even reversing in young adult age groups in the UK and the Netherlands (Allender et al., 2008; Vaartjes et al., 2011).

As observed in Figures 2 and 3, in some countries the historical values $v^{1}$ have flattened out in recent years. This is more notable in populations where the yearly survival probabilities have reached higher levels, namely for females, especially in Japan and UK. This observation suggests that mortality rates

\footnotetext{
${ }^{1}$ www.mortality.org
} 

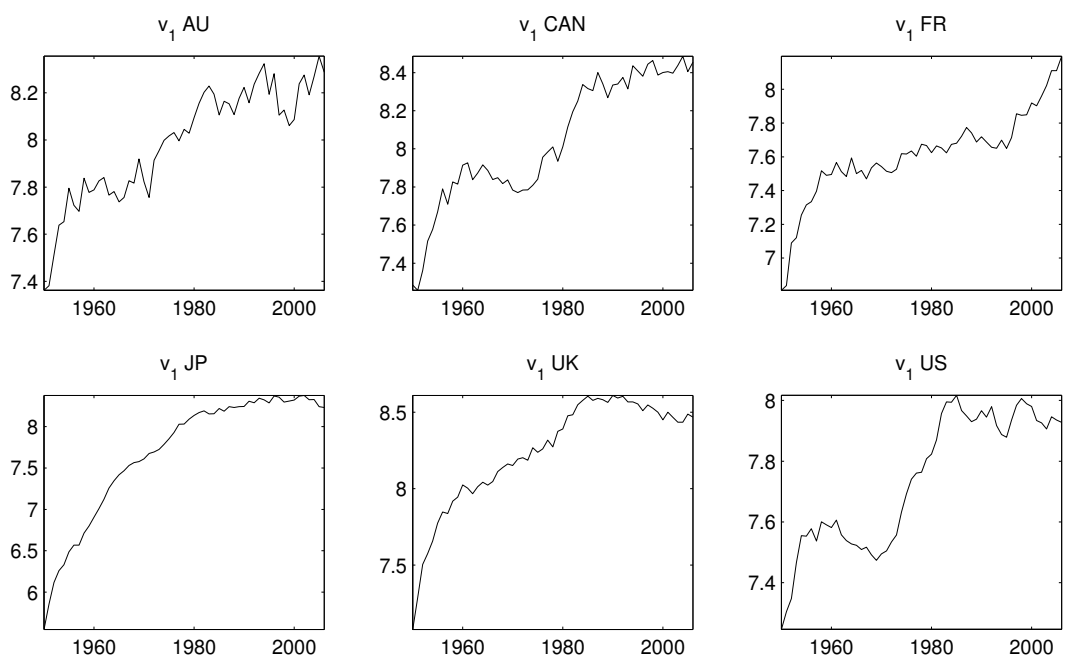

Figure 2: Historical values for risk factor $v^{1}$, females. Note the different scales.
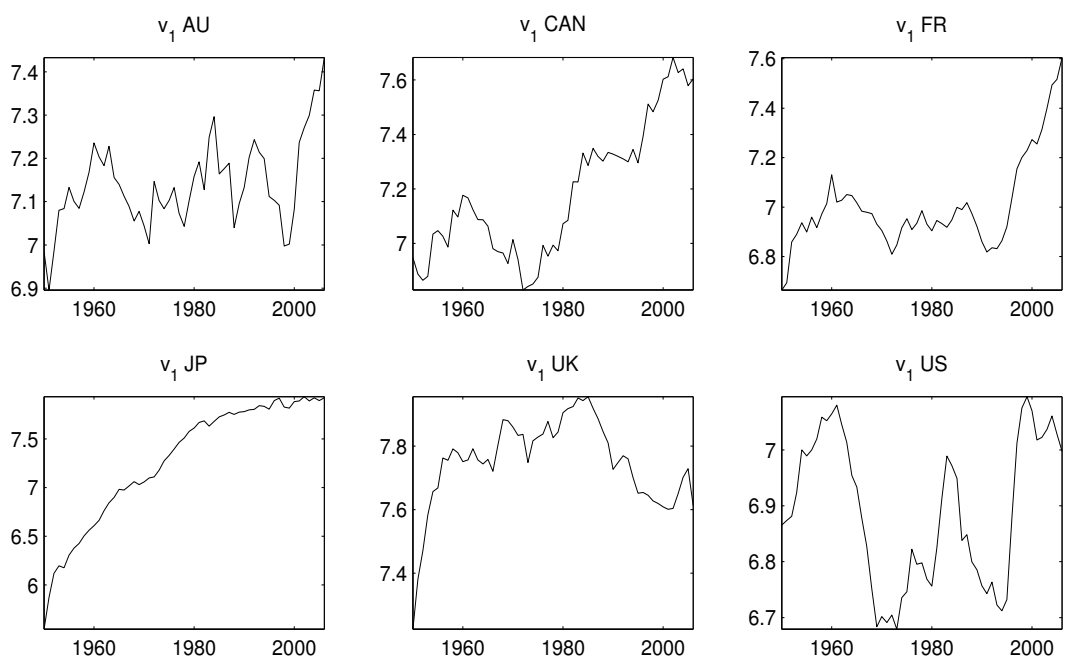

Figure 3: Historical values for risk factor $v^{1}$, males. Note the different scales.

may start to stabilize when they reach certain levels, a phenomenon suggested already in Wicksell (1926)

In order to analyse Wicksell's conjecture, we fit the equation

$$
\Delta v_{t}^{1}=b+a v_{t-1}^{1}
$$

by OLS regression into the historical values of $v^{1}$ for each country. When $a \in$ $(0,2)$, equation (4) corresponds to mean-reverting behaviour with equilibrium level $\bar{v}=-\frac{b}{a}$. When $v^{1} \leq \bar{v}$, the right-hand side of the equation is positive, and 
it tends to zero as $v^{1}$ approaches $\bar{v}$.

While equation (4) with $a \in(0,2)$ corresponds to a stationary time series in the long run, it is clear that none of the series in Figures 2 and 3 is stationary over the observed period (this is confirmed by statistical tests). This illustrates the general challenge in mortality modelling, where one is trying to model the long range behavior of uncertain data coming from a system in a state of transition. There is reason to believe that the characteristics of the underlying process will change in the future but such information is not necessarily contained in historical data.

Table 1: Parameter estimates, t-values and summary statistics for $\Delta v_{t}^{1}=b+a v_{t-1}^{1}$.

\begin{tabular}{c|cccccc}
\hline & AU & CAN & F & JP & UK & US \\
\hline \hline Female & & & & & & \\
\hline$b$ & 0.778 & 0.446 & 0.569 & 0.614 & 0.902 & 0.437 \\
p-value (t-statistic) & 0.017 & 0.028 & 0.020 & 0.000 & 0.000 & 0.015 \\
$a$ & -0.095 & -0.053 & -0.072 & -0.074 & -0.107 & -0.055 \\
p-value (t-statistic) & 0.020 & 0.036 & 0.026 & 0.000 & 0.000 & 0.018 \\
& & & & & & \\
$R^{2}$ & 0.097 & 0.079 & 0.089 & 0.627 & 0.461 & 0.100 \\
Adj. $R^{2}$ & 0.080 & 0.062 & 0.072 & 0.620 & 0.451 & 0.083 \\
p-value (F-Statistic) & 0.020 & 0.036 & 0.026 & 0.000 & 0.000 & 0.018 \\
\hline Male & & & & & & \\
\hline$b$ & 1.149 & 0.101 & -0.182 & 0.518 & 1.475 & 0.439 \\
p-value (t-statistic) & 0.075 & 0.686 & 0.549 & 0.000 & 0.000 & 0.207 \\
$a$ & -0.160 & -0.012 & 0.028 & -0.065 & -0.189 & -0.063 \\
p-value (t-statistic) & 0.077 & 0.721 & 0.513 & 0.000 & 0.000 & 0.209 \\
$R^{2}$ & & & & & & \\
Adj. $R^{2}$ & 0.057 & 0.002 & 0.008 & 0.417 & 0.273 & 0.029 \\
p-value (F-Statistic) & 0.039 & -0.016 & -0.010 & 0.406 & 0.259 & 0.011 \\
\hline
\end{tabular}

Notes. The table reports coefficient estimates for the regression, and the p-values of their $t$ -statistics. A low p-value supports rejection of the null hypothesis that the coefficient is equal to zero. The F-statistic tests for the joint significance of regressors. A low p-value of the F-statistic supports rejection of the null hypothesis that all equation coefficients are equal to zero.

Estimates for parameters $a$ and $b$ along with regression diagnostics are presented in Table 1. For women the parameter estimates of $a$ are negative in all countries, with p-values of the respective t-test statistics below 0.05. In the case of males, $a<0$ for all countries except for France. For Australia, Japan and UK the p-values for the regression coefficients are below 0.08. Table 2 reports results for the residual tests. The basic assumptions of linear regression (independence, homoscedasticity, normality; see e.g. Hamilton (1994)) are fulfilled, apart from some indication of serial correlation. Stationarity and unit root tests indicate stationarity and absence of unit roots in the residual time series.

Overall, equation (4) fits well into the historical data of many of the countries. It may thus serve as a reasonable model for survival probability of young adults if one shares Wicksell's views on the stabilization of mortality rates in the long run. The better fit for females may be explained by the fact that female mortality is generally lower than male mortality, and may thus be closer already to its equilibrium level. 
Table 2: Residual test statistics for the regression $\Delta v_{t}^{1}=b+a v_{t-1}^{1}$.

\begin{tabular}{|c|c|c|c|c|c|c|}
\hline & $\mathrm{AU}$ & $\mathrm{CAN}$ & $\mathrm{F}$ & JP & UK & US \\
\hline \multicolumn{7}{|l|}{ Female } \\
\hline Serial correlation (BG) & 0.329 & 0.533 & 0.123 & 0.731 & 0.084 & 0.044 \\
\hline Normality (JB) & 0.450 & 0.364 & 0.170 & 0.484 & 0.692 & 0.481 \\
\hline Heteroskedasticity (BP) & 0.546 & 0.307 & 0.074 & 0.013 & 0.029 & 0.263 \\
\hline ADF t-statistic & -9.191 & -8.374 & -8.105 & -7.11 & -3.722 & -4.474 \\
\hline p-value & ¡ 0.01 & ¡ 0.01 & ¡ 0.01 & ¡ 0.01 & ¡ 0.01 & ¡ 0.01 \\
\hline KPSS level & 0.219 & 0.164 & 0.394 & 0.086 & 0.255 & 0.139 \\
\hline p-value & ¿ 0.1 & ¿ 0.1 & 0.080 & ¿. 0.1 & ¿. 0.1 & ¿. 0.1 \\
\hline \multicolumn{7}{|l|}{ Male } \\
\hline Serial correlation (BG) & 0.364 & 0.551 & 0.146 & 0.349 & 0.167 & 0.000 \\
\hline Normality (JB) & 0.920 & 0.221 & 0.595 & 0.001 & 0.543 & 0.113 \\
\hline Heteroskedasticity (BP) & 0.781 & 0.151 & 0.519 & 0.001 & 0.697 & 0.311 \\
\hline ADF statistic & -7.008 & -8.443 & -5.802 & -6.945 & -5.155 & -4.6 \\
\hline p-value & ¡ 0.01 & ¡ 0.01 & ¡ 0.01 & ¡ 0.01 & ¡ 0.01 & ¡ 0.01 \\
\hline KPSS statistic & 0.219 & 0.221 & 0.267 & 0.134 & 0.843 & 0.128 \\
\hline p-value & ¿ 0.1 & ¿ 0.1 & ¿ 0.1 & ¿. 0.1 & ¿ 0.1 & ¿. 0.1 \\
\hline
\end{tabular}

Notes. For serial correlation, normality and heteroskedasticity tests, the numbers are pvalues of the statistics in the first column. Serial correlation is tested with the BreuschGodfrey tests for up to fourth-order serial correlation. A small p-value suggests lack of serial correlation. Normality is tested with the Jarque-Bera test, with null hypothesis of normality. A large p-value supports the normality assumption. The Breusch-Pagan test tests against heteroskedasticity, with the null hypothesis of homoskedasticity. A large p-value indicates absence of heteroskedasticity. Stationarity of the residuals is tested with the augmented Dickey-Fuller(ADF) and Kwiatkowski-Phillips-Schmidt-Shin (KPSS) tests. The ADF unit root regressions do not include deterministic terms, and the number of lags was selected by their significance (10\% level) with a maximum number of lags $(10)$, determined by the method suggested by Schwert (1989). For KPSS test, the null hypothesis was level stationarity.

\subsection{Risk factor $v^{2}$}

The significant reduction in coronary disease is a key contributor to the rapid increase in the survival probalility of the middle-aged population during recent decades. This effect is also reflected in risk factor $v^{2}$ (see Figures 4 and 5) corresponding to the survival probability of 50-year-olds. In Ford et al. (2007); Preston and Wang (2006), approximately half of the improvement is attributed to medical treatments, and the remaining half to reductions in other factors, such as blood pressure, cholesterol and smoking prevalence. In the future, both novel medical innovations and wider availability of treatment, as well as possible further reductions in smoking, are likely to contribute to the improvement of $v^{2}$. On the other hand, these advances may to some extent be outweighed by the detrimental effects of obesity and other lifestyle-related factors (Schroeder, 2007; Olshansky et al., 2005). Consequently, it is possible that $v^{2}$ will level out in the future.

As the historical values are generally not showing signs of stabilizing, we simply fit a trend into $v^{2}$ in order to quantify the rate of improvement of the historical values of $v^{2}$ :

$$
\Delta v^{2}=b .
$$

Results are presented in Tables 3 and 4 . The p-values of the t-tests for parameter $b$ in all sample countries are 0.001 or smaller. In some cases the test statistics 

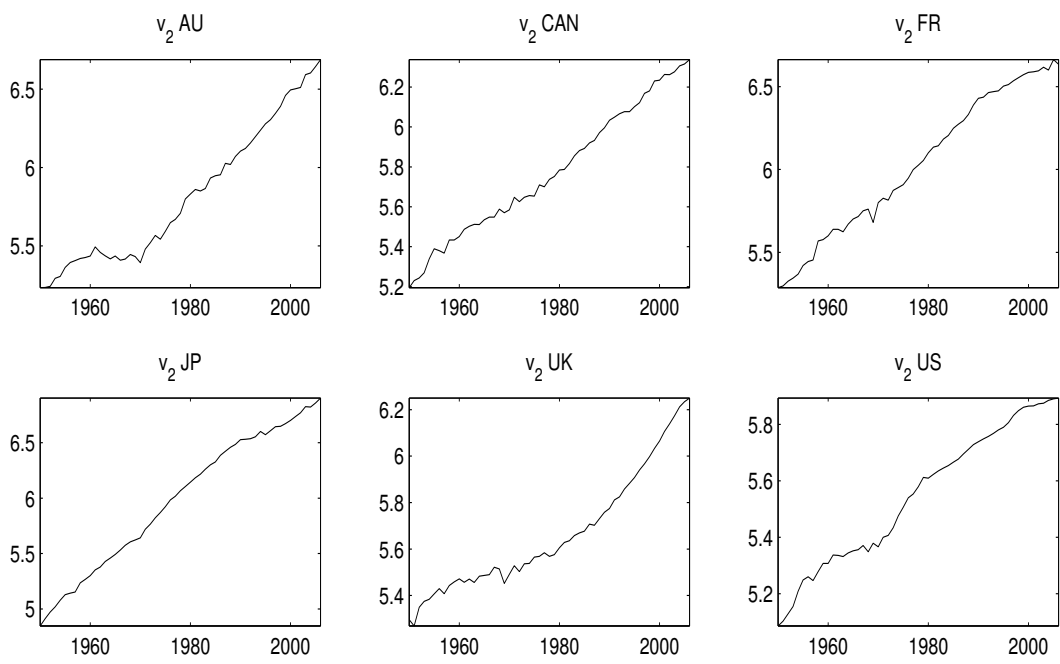

Figure 4: Historical values for risk factor $v^{2}$, females. Note the different scales.
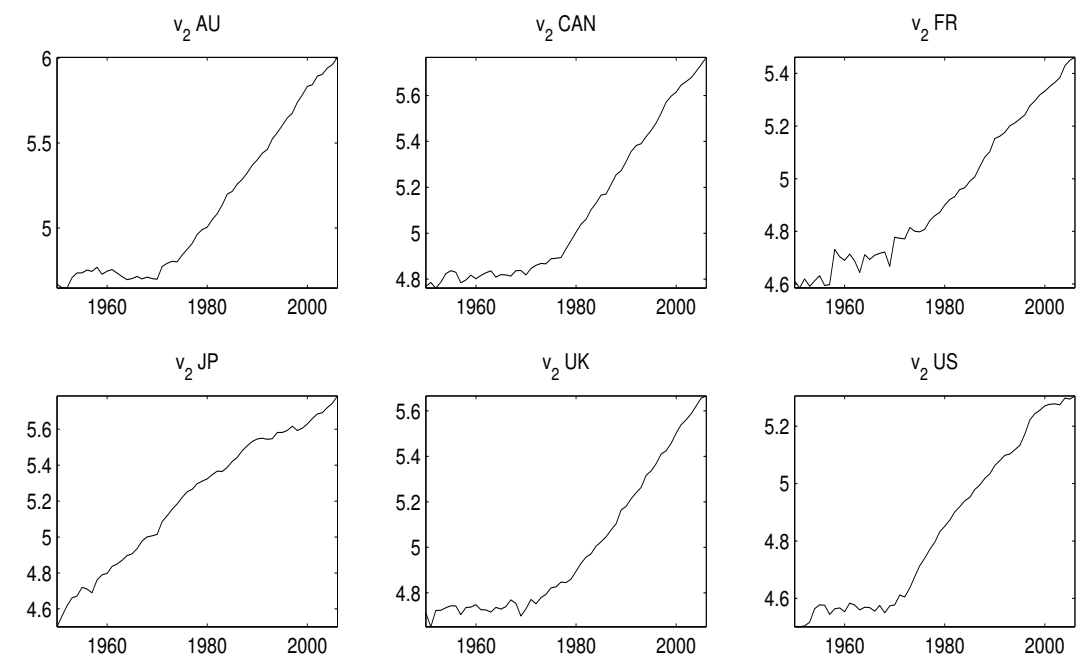

Figure 5: Historical values for risk factor $v^{2}$, males. Note the different scales.

for residuals indicate some serial correlation and non-normality but stationarity and absense of unit roots are well supported.

\subsection{Risk factor $v^{3}$}

Pension plans and other mortality-linked instruments are often connected with old-age mortality, which has received wide attention in literature e.g. (Thatcher, 1999; Mesl and Vallin, 2006; Kannisto et al., 1994; Vallin and Mesl, 2004). In our model, risk factor $v^{3}$ describes the mortality of the 100-year-old. Figures 
Table 3: Parameter estimates and p-values for $\Delta v_{t}^{2}=b$.

\begin{tabular}{c|cccccc}
\hline & AU & CAN & F & JP & UK & US \\
\hline \hline Female & 0.026 & 0.020 & 0.024 & 0.037 & 0.017 & 0.014 \\
p-value & 0.000 & 0.000 & 0.000 & 0.000 & 0.000 & 0.000 \\
Male & 0.024 & 0.018 & 0.015 & 0.023 & 0.017 & 0.014 \\
p-value & 0.000 & 0.000 & 0.001 & 0.000 & 0.000 & 0.000 \\
\hline
\end{tabular}

Table 4: Residual test statistics for $\Delta v_{t}^{2}=b_{2}$.

\begin{tabular}{|c|cccccc|}
\hline & & & & & & \\
& AU & CAN & F & JP & UK & US \\
\hline \hline Female & & & & & & \\
\hline Serial correlation (BG) & 0.406 & 0.121 & 0.017 & 0.144 & 0.079 & 0.422 \\
Normality (JB) & 0.803 & 0.502 & 0.000 & 0.023 & 0.000 & 0.662 \\
Heteroskedasticity (GQ) & 0.887 & 0.999 & 0.998 & 0.372 & 1 & 1 \\
\hline ADF t-statistic & -6.376 & -10.236 & -10.067 & -4.863 & -2.109 & -7.276 \\
p-value & $i 0.01$ & $i 0.01$ & $i 0.01$ & $i 0.01$ & 0.037 & $i 0.01$ \\
KPSS level & 0.459 & 0.059 & 0.227 & 0.752 & 0.772 & 0.333 \\
p-value & 0.052 & $i 0.1$ & $i 0.1$ & $i 0.1$ & $i 0.1$ & $i 0.1$ \\
\hline Male & & & & & & \\
\hline Serial correlation (BG) & 0.006 & 0.016 & 0.025 & 0.336 & 0.043 & 0.150 \\
Normality (JB) & 0.497 & 0.018 & 0.000 & 0.640 & 0.000 & 0.437 \\
Heteroskedasticity (GQ) & 0.998 & 0.998 & 1 & 0.977 & 1 & 0.997 \\
\hline ADF t-statistic & -2.564 & -2.106 & -10.376 & -7.076 & -1.688 & -6.13 \\
p-value & 0.012 & 0.037 & $i 0.01$ & $i 0.01$ & 0.089 & $i 0.01$ \\
KPSS level & 1.199 & 1.268 & 0.384 & 0.395 & 1.456 & 0.507 \\
p-value & $i 0.1$ & $i 0.1$ & 0.084 & 0.080 & $i 0.1$ & 0.040 \\
\hline
\end{tabular}

Notes. See Table 2 for descriptions of the test statistics. The Breusch-Pagan test, which is considered more robust, was not applicable here as it regresses squared residuals on the independent variables. It was replaced by the Goldfeld-Quant test.

As the more robust Breusch-Pagan test regresses the squared residuals on the independent variables which do not exist here, it was not applicable, and was replaced by the GoldfeldQuant test.

6 and 7 show that old-age mortality has generally improved in the past, with some strong fluctuations. A striking feature is that, in particular for US and Canadian males, to some extent US females, the development has been very rapid in the 21st century. This phenomenon was also recognized in Rau et al. (2008).

Reductions in mortality in general and old-age mortality in particular are generally linked with reductions in smoking (Preston and Wang, 2006; Doll et al., 2004; Cairns and Kleinow, 2011). Another contributor suggested by Ho and Preston (2010) is the intensive deployment of life-saving technologies by the US health care system at very old ages, which has contributed to the mortality improvements of the old, particularly in comparison to other countries. These factors could also explain the recent rapid development in the risk factor $v^{3}$ of US males.

Preston (2007) has investigated mechanisms that link mortality to the level of national income. The rationale behind such a connection is that a higher income facilitates increased consumption of goods and services with health benefits. 

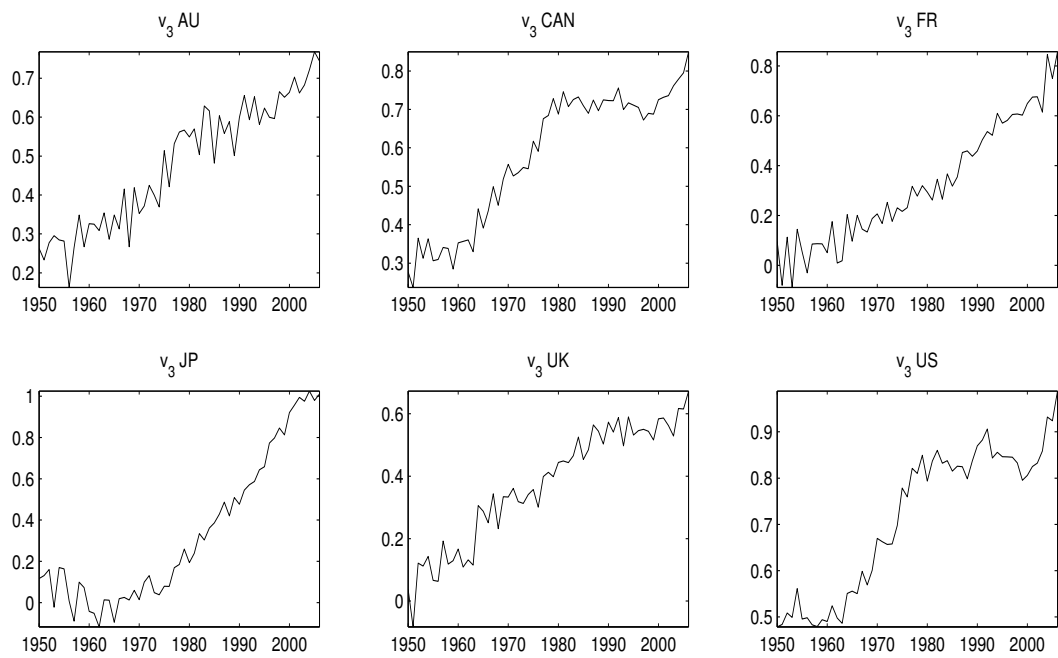

Figure 6: Historical values for risk factor $v^{3}$, females. Note the different scales.
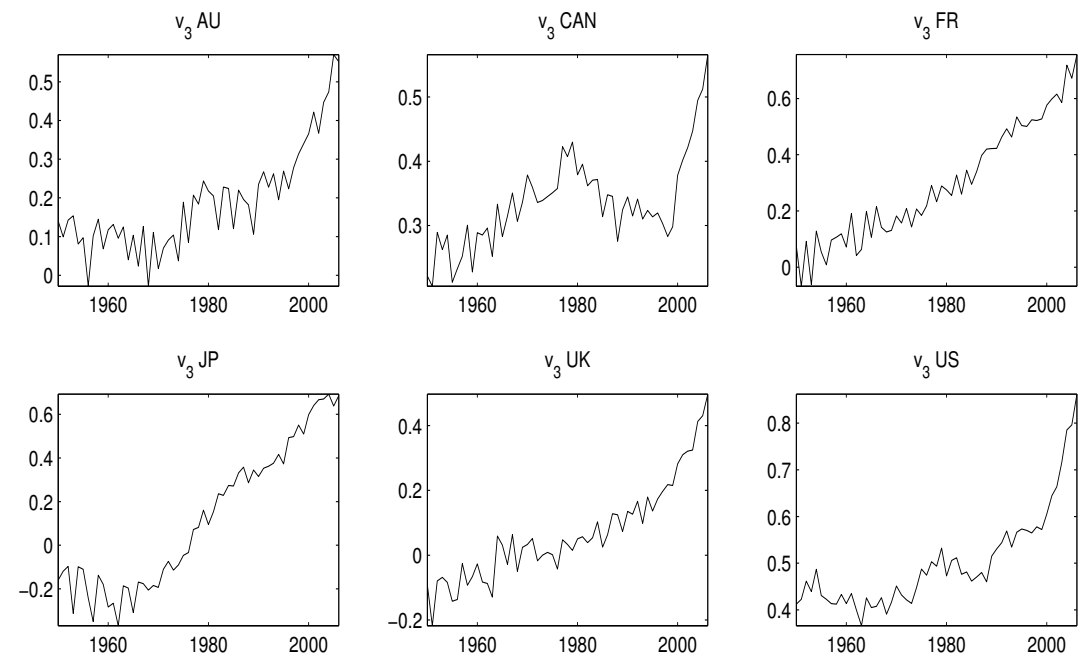

Figure 7: Historical values for risk factor $v^{3}$, males. Note the different scales.

The long-term connection between national income and mortality has also been discussed e.g. in Rodgers (1979); Cutler et al. (2006); Preston (2007); Barrieu et al. (to appear); Hanewald (2011b). Figure 8 presents the logarithms of real GDP per capita in the sample countries. The GDP data was obtained from Maddison (2011). Similarities in the general shape of the plots for log per capita GDP and $v^{3}$, especially for those of females, suggest that the long-term movements of $v^{3}$ and log-per capita GDP may indeed be connected. 

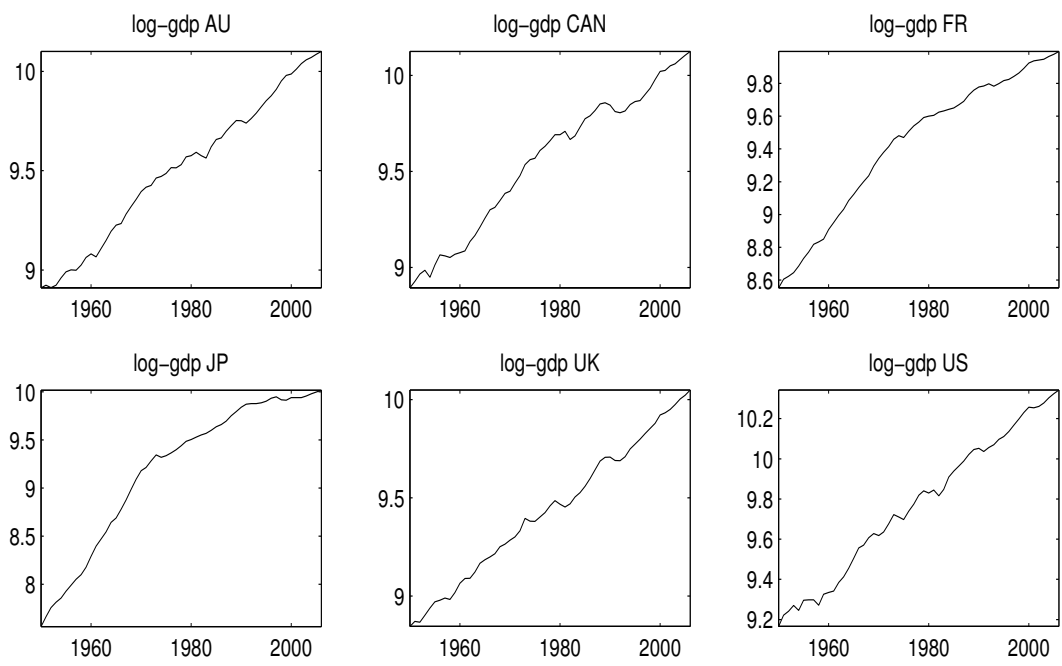

Figure 8: Logarithm of per capita GDP by country. Note the different scales.

We analyse the dependence of $v^{3}$ on GDP with the regression

$$
\Delta v_{t}^{3}=b+a_{1} v_{t-1}^{3}+a_{2} g_{t-1},
$$

where $g_{t}$ is the logarithm of per capita GDP. The interpretation is that the drift of $v_{t}^{3}$ depends on its relation to $g_{t}$. If $a_{1}<0$ and $a_{2}>0$, the drift increases if $v_{t}^{3}$ lags behind $g_{t}$.

Tables 5 and 6 present the regression results. Coefficients $a_{1}$ are negative and $a_{2}$ positive for all regressions except for US males for the entire observation period. Because of the exceptionally rapid recent growth in $v^{3}$ of US males, we performed the regressions for an additional truncated period of 1950-2000, in order to inspect the dependence between $v^{3}$ and GDP before this unusual development. For the truncated period $a_{1}$ is negative and $a_{2}$ positive, like for other regressions. The p-values for all regression coefficients, but those of Japanese females, are below 0.05. Residual test statistics indicate that, in general, the basic assumptions of linear regression are fulfilled, apart from some indication for heteroscedasticity and non-normality. All in all, the results support the hypothesis that the long-term increases in gdp have a positive effect on old-age mortality.

The plots of GDP and $v^{2}$ also somewhat resemble each other, but performing the above analysis performed on $v^{2}$ did not yield equally good results. 
Table 5: Parameter estimates, t-values and summary statistics for the regression $\Delta v_{t}^{3}=b+a_{1} v_{t-1}^{3}+a_{2} g_{t-1}$.

\begin{tabular}{c|ccccccc}
\hline & AU & CAN & F & JP & UK & US & \\
\hline Female & & & & & & & \\
\hline$b$ & -3.062 & -1.686 & -1.826 & -0.332 & -2.894 & -0.664 & \\
p-value (t-statistic) & 0.000 & 0.000 & 0.001 & 0.053 & 0.000 & 0.020 & \\
$a_{1}$ & -0.877 & -0.455 & -0.388 & -0.057 & -0.656 & -0.189 & \\
p-value (t-statistic) & 0.000 & 0.000 & 0.001 & 0.1941 & 0.000 & 0.015 & \\
$a_{2}$ & 0.367 & 0.205 & 0.208 & 0.040 & 0.334 & 0.083 & \\
p-value (t-statistic) & 0.001 & 0.000 & 0.001 & 0.044 & 0.000 & 0.016 & \\
& & & & & & & \\
$R^{2}$ & 0.454 & 0.255 & 0.195 & 0.076 & 0.335 & 0.109 & \\
Adj. $R^{2}$ & 0.433 & 0.227 & 0.164 & 0.041 & 0.310 & 0.076 & \\
p-value (F-Statistic) & 0.000 & 0.000 & 0.003 & 0.124 & 0.000 & 0.046 & \\
\hline Male & & & & & & & US trunc \\
\hline$b$ & -1.212 & -0.273 & -1.359 & -0.494 & -1.803 & -0.238 & -0.421 \\
p-value(t-statistic) & 0.001 & 0.091 & 0.003 & 0.029 & 0.001 & 0.143 & 0.009 \\
$a_{1}$ & -0.405 & -0.234 & -0.335 & -0.121 & -0.456 & 0.002 & -0.341 \\
p-value(t-statistic) & 0.001 & 0.034 & 0.003 & 0.042 & 0.001 & 0.976 & 0.003 \\
$a_{2}$ & 0.136 & 0.037 & 0.156 & 0.057 & 0.195 & 0.025 & 0.060 \\
p-value(t-statistic) & 0.001 & 0.054 & 0.003 & 0.024 & 0.001 & 0.197 & 0.004 \\
$R^{2}$ & & & & & & & \\
Adj. $R^{2}$ & 0.207 & 0.089 & 0.164 & 0.093 & 0.202 & 0.088 & 0.1853 \\
p-value(F-Statistic) & 0.177 & 0.055 & 0.132 & 0.059 & 0.172 & 0.054 & 0.1506 \\
\hline
\end{tabular}

Notes. See Table 1 for description of the test statistics.

Table 6: Residual test statistics for the regression $\Delta v_{t}^{3}=b+a_{1} v_{t-1}^{3}+a_{2} g_{t-1}$.

\begin{tabular}{|c|c|c|c|c|c|c|c|}
\hline & $\mathrm{AU}$ & CAN & $\mathrm{F}$ & JP & UK & US & \\
\hline \multicolumn{8}{|l|}{ Female } \\
\hline Serial correlation (BG) & 0.000 & 0.002 & 0.000 & 0.000 & 0.090 & 0.26 & \\
\hline Normality (JB) & 0.536 & 0.279 & 0.009 & 0.203 & 0.880 & 0.533 & \\
\hline Heteroskedasticity (BP) & 0.330 & 0.038 & 0.101 & 0.001 & 0.012 & 0.734 & \\
\hline ADF t-statistic & -7.356 & -3.921 & -1.172 & -10.599 & -6.843 & -8.499 & \\
\hline p-value & ¡ 0.01 & ¡ 0.01 & ¿ 0.1 & ¡ 0.01 & ¡ 0.01 & ¡ 0.01 & \\
\hline KPSS level & 0.120 & 0.312 & 0.463 & 0.084 & 0.263 & 0.150 & \\
\hline p-value & ¿ 0.1 & ¿ 0.1 & 0.050 & ¿ 0.1 & ¿ 0.1 & ¿ 0.1 & \\
\hline Male & & & & & & & US trunc \\
\hline Serial correlation (BG) & 0.001 & 0.022 & 0.000 & 0.000 & 0.113 & 0.035 & 0.059 \\
\hline Normality (JB) & 0.284 & 0.759 & 0.1993 & 0.075 & 0.220 & 0.756 & 0.716 \\
\hline Heteroskedasticity (BP) & 0.865 & 0.674 & 0.007 & 0.0003 & 0.498 & 0.235 & 0.366 \\
\hline ADF t-statistic & -9.475 & -8.919 & -1.336 & -10.512 & -3.329 & -8.569 & -7.607 \\
\hline p-value & ¡ 0.01 & 0.01 & ¿. 0.1 & ¡ 0.01 & ¡ 0.01 & ¡ 0.01 & ¡ 0.01 \\
\hline KPSS level & 0.293 & 0.171 & 0.446 & 0.118 & 0.272 & 0.135 & 0.176 \\
\hline p-value & ¿ 0.1 & ¿ 0.1 & 0.057 & ¿ 0.1 & ¿ 0.1 & ¿ 0.1 & ¿ 0.1 \\
\hline
\end{tabular}

Notes. See Table 2 for description of the test statistics. 


\subsection{GDP and financial markets}

It is generally accepted that GDP is connected with financial markets; see Stock and Watson (2003) for a review. In particular, the term spread, which is broadly defined as the difference between long and short-term interest rates, seems to be linked with changes in economic activity; see e.g. Wheelock and Wohar (2009). Also, GDP appears to be strongly connected with credit spreads, which reflect how the market perceives default risk; see Duffie and Singleton (2003). In addition, there is evidence of a link between stock prices and GDP; see e.g. Fischer and Merton (1985); Bosworth et al. (1975).

This section illustrates how such connections can be conveniently analysed in terms of simple linear regressions. Combined with the results of the previous sections, we obtain a link between mortality and financial markets. As an example, we analyse the connections of US GDP to the US government and corporate bond markets.

Figure 9 shows the term spreads, the log GDP differences, and the credit spreads for the period of 1953-2006. The term spread is the difference between US treasury constant maturity rates of 5 years and one year, and credit spread the difference between Moody's seasoned corporate bond yields with ratings BAA and AAA. All interest rate data is end-of-year values from FRED Federal Reserve Economic Data (2011a,b,c,d). We observe that the log-gdp difference curve often moves in the same direction as term spread, and in opposite direction from credit spread.
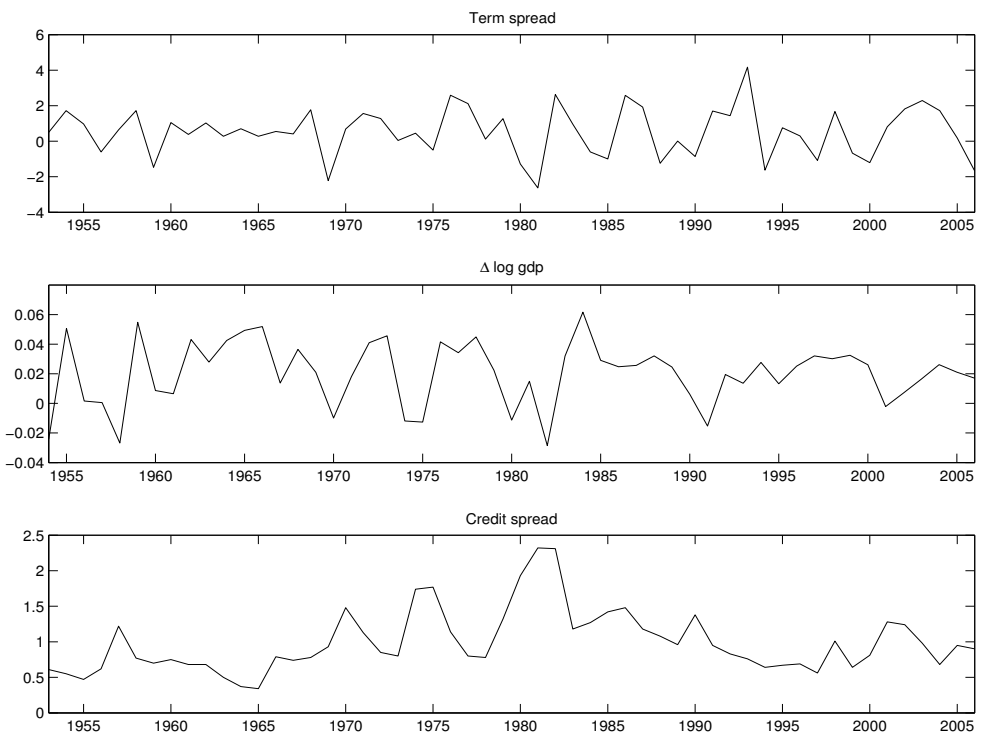

Figure 9: Term spread, differenced log-GDP and credit spread.

Combining the findings of e.g. Wheelock and Wohar (2009) for term spread and Duffie and Singleton (2003) for credit spread, we study the connection of US log per capita GDP $g_{t}$ to both term spread $s_{t}^{T}$ and credit spread $s_{t}^{C}$ with 
the equation

$$
\Delta g_{t}=b+a_{1} s_{t-1}^{T}+a_{2} s_{t-1}^{C},
$$

When $a_{1}>0$, large term spreads anticipate high GDP growth rates. In other words, a large difference between long and short term interest rates predicts strong economic growth, and vice versa. When $a_{2}<0$, large credit spreads precede small GDP growth rates. This means that a large difference between interest rates for assets of different riskiness predicts slower economic growth, and vice versa.

In this work we choose, with later simulation applications in mind, to define term spread as the differences between log-interest rates. Similarly, we define credit spread as the logarithm of the differences between log-interest rates. Using log-rates ensures that the interest rates remain nonnegative in simulations, and using a log-spread ensures that the credit spread remains nonnegative as well. The rates used for term spread $s_{t}^{T}$ and credit spread $s_{t}^{C}$ are as above.

Regression results are presented in Table 7 . Parameter estimates are positive for $b$ and $a_{1}$ and negative for $a_{2}$, which is in line with earlier findings. Corresponding t-tests produce very small p-values. The regression diagnostics are in line with the requirements of the ordinary least squares regression, apart from some indication of serial correlation. In addition, unit root and stationarity tests suggest that the residuals are stationary.

Table 7: Parameter estimates, t-values and summary statistics for the regression $\Delta g_{t}=$ $b+a_{1} s_{t-1}^{T}+a_{2} s_{t-1}^{C}$.

\begin{tabular}{c|c||c|c}
\hline \hline$b$ & -0.045 & Serial Correlation (BG) & 0.975 \\
p-value(t-statistic) & 0.040 & Normality (JB) & 0.632 \\
$a_{1}$ & 0.028 & Heteroskedasticity (BP) & 0.254 \\
p-value(t-statistic) & 0.047 & & \\
$a_{2}$ & -0.030 & & \\
p-value(t-statistic) & 0.005 & & \\
& & ADF t-statistic & -0.950 \\
$R^{2}$ & 0.17 & p-value & $i 0.01$ \\
Adj. $R^{2}$ & 0.14 & KPSS level & 0.280 \\
p-value(F-Statistic) & 0.009 & p-value & $i 0.1$ \\
\hline \hline
\end{tabular}

Notes. See Tables 1 and 2 for descriptions of the test statistics.

For later use, we fit the equation

$$
\Delta s_{t}^{T}=b+a s_{t-1}^{T},
$$

into US term spread data. This is analogous to the mean reverting interest rate model of Vasicek (1977). From the results in Table 9 we observe that the model fits the data well, although residual diagnostics do not support the normality hypothesis. 
Table 8: Parameter estimates, t-values and summary statistics for the regression $\Delta s_{t}^{T}=b+a s_{t-1}^{T}$.

\begin{tabular}{c|c||c|c}
\hline & & \\
\hline \hline$b$ & 0.049 & Serial Correlation (BG) & 0.022 \\
p-value(t-statistic) & 0.093 & Normality (JB) & 0.000 \\
$a$ & -0.429 & Heteroskedasticity (BP) & 0.100 \\
p-value(t-statistic) & 0.000 & & \\
& & ADF t-statistic & -0.771 \\
$R^{2}$ & 0.209 & p-value & $i 0.01$ \\
Adj. $R^{2}$ & 0.1931 & KPSS level & 0.274 \\
p-value(F-Statistic) & 0.000 & p-value & $i 0.1$ \\
\hline \hline
\end{tabular}

Notes. See Tables 1 and 2 for descriptions of the test statistics.

Similarly, we fit the equation

$$
\Delta s_{t}^{C}=b+a s_{t-1}^{C},
$$

into the credit spread data. From the results in Table 9 we observe that the model describes the data reasonably well, although residual diagnostics indicate a possibility of serial correlation.

Table 9: Parameter estimates, t-values and summary statistics for the regression $\Delta s_{t}^{C}=b+a s_{t-1}^{C}$.

\begin{tabular}{c|c||c|c}
\hline & & \\
\hline \hline$b$ & -1.188 & Serial Correlation (BG) & 0.646 \\
p-value(t-statistic) & 0.000 & Normality (JB) & 0.826 \\
$a$ & -0.571 & Heteroskedasticity (BP) & 0.580 \\
p-value(t-statistic) & 0.000 & & \\
& & ADF t-statistic & -0.972 \\
$R^{2}$ & 0.3028 & p-value & $i 0.01$ \\
Adj. $R^{2}$ & 0.2891 & KPSS level & 0.138 \\
p-value(F-Statistic) & 0.000 & p-value & $i 0.1$ \\
\hline \hline
\end{tabular}

Notes. See Tables 1 and 2 for descriptions of the test statistics.

\section{Modelling the risk factors}

Based on the observations in the previous section, we propose to model the mortality risk factors, GDP and the interest rate spreads with the system of equations 


$$
\begin{aligned}
\Delta v_{t}^{f, 1} & =a^{11} v_{t-1}^{f, 1}+b^{1}+\varepsilon_{t}^{1} \\
\Delta v_{t}^{f, 2} & =b^{2}+\varepsilon_{t}^{2} \\
\Delta v_{t}^{f, 3} & =a^{33} v_{t-1}^{f, 3}+a^{37} g_{t-1}+b^{3}+\varepsilon_{t}^{3} \\
\Delta v_{t}^{m, 1} & =a^{44} v_{t-1}^{m, 1}+b^{4}+\varepsilon_{t}^{4} \\
\Delta v_{t}^{m, 2} & =b^{5}+\varepsilon_{t}^{5} \\
\Delta v_{t}^{m, 3} & =a^{66} v_{t-1}^{m, 3}+a^{67} g_{t-1}+b^{6}+\varepsilon_{t}^{6} \\
\Delta g_{t} & =a^{78} s_{t-1}^{T}+a^{79} s_{t-1}^{C}+b^{7}+\varepsilon_{t}^{7} \\
\Delta s_{t}^{T} & =a^{88} s_{t-1}^{T}+b_{8}+\varepsilon_{t}^{8} \\
\Delta s_{t}^{C} & =a^{99} s_{t-1}^{C}+b_{9}+\varepsilon_{t}^{9}
\end{aligned}
$$

where $\varepsilon_{t}^{i}$ are random variables describing the unexpected fluctuations in the risk factors. As before, $v_{t}^{f, i}$ and $v_{t}^{m, i}$ are mortality risk factors for males and females, $g_{t} \log$ GDP per capita, $s_{t}^{T}$ term spread and $s_{t}^{C}$ the credit spread.

The above system can be written as a linear multivariate stochastic difference equation

$$
\Delta x_{t}=A x_{t-1}+b+\varepsilon_{t},
$$

where $x=\left[v_{t}^{f, 1}, v_{t}^{f, 2}, v_{t}^{f, 3}, v_{t}^{m, 1}, v_{t}^{m, 2}, v_{t}^{m, 3}, g_{t}, s_{t}^{T}, s_{t}^{C}\right], A \in \mathbb{R}^{9 \times 9}, b \in \mathbb{R}^{9}$, and $\varepsilon_{t}$ are $\mathbb{R}^{9}$-valued random vectors. This compact formulation is straightforward to study, both analytically and numerically.

In order to model the random vectors $\varepsilon_{t}$, we examine the residuals of regression equations in Section 3 for US data. Due to the availability of US Treasury Constant Maturity data from 1953 onwards only, we used the residuals for the period 1953-2006 to estimate $\varepsilon_{t}$. Except for the interest rate spreads, the residuals appear to follow a Gaussian distribution; see Tables 2, 4 and 6. The correlation matrix $R \in \mathbb{R}^{9 \times 9}$ and standard deviation vector $\sigma \in \mathbb{R}^{9}$ are given below. In matrix $R$, the corresponding p-values for t-tests with null hypothesis of no correlation are given in parenthesis.

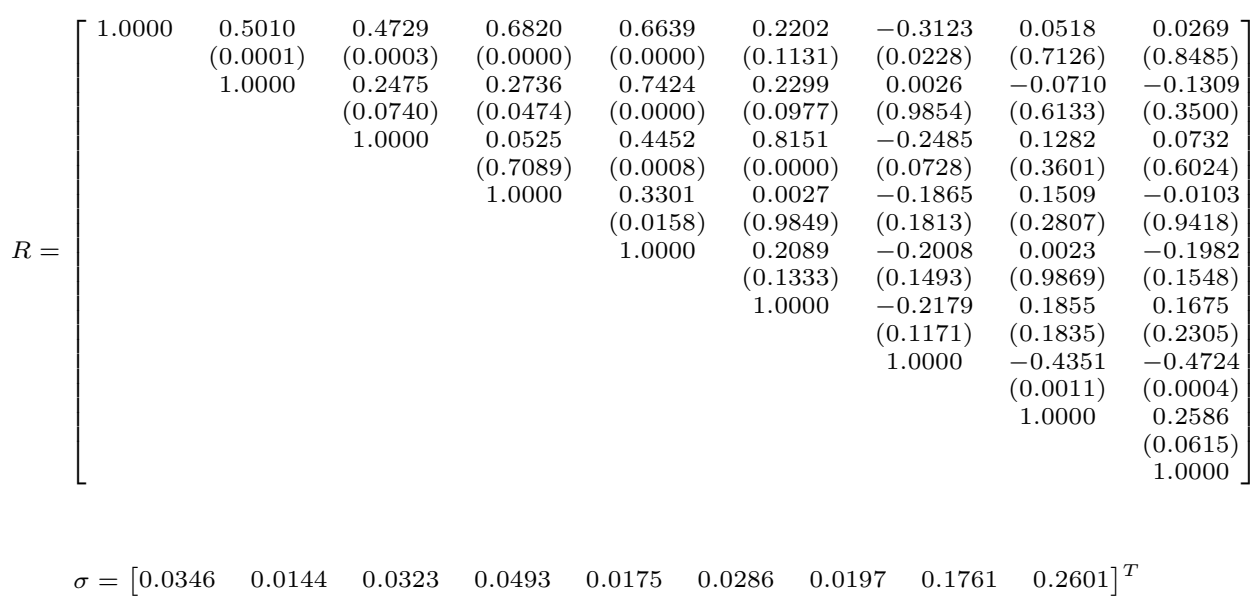


Correlations between many of the residuals seem to deviate significantly from zero. Thus, in addition to the long-terms relations described by the system equations, there seem to be short-term links between the risk factors. In particular, the residuals of equations for $\Delta v_{t}^{f, 1}$ and $\Delta v_{t}^{f, 3}$ have negative correlations with the residuals of $\Delta g_{t}$. This suggests that mortality is procyclical with economic growth, a phenomenon also observed in Ruhm (2000); Tapia Granados (2005a,b); Hanewald (2011b). Moreover, the residuals for $\Delta s_{t}^{T}$ and $\Delta s_{t}^{C}$ are negatively correlated with those of $\Delta g_{t}$, with relatively low p-values.

Several of the correlation coefficients between residuals for mortality risk factors $v_{t}^{i}$ also have small p-values. For instance, the residuals for $\Delta v_{t}^{f, 1}$ are positively correlated with the residuals for all other $\Delta v_{t}^{i}$ s, except for $\Delta v_{t}^{m, 3}$. This is a plausible phenomenon, as mortality rates across age groups are likely to depend on some common factors.

In order to better capture the uncertainties in mortality from the available data, we will next study the residuals $\varepsilon_{t}$ on a global level, using the data set from Section 3 for six countries over the years 1950-2006. Due to the lack of sufficient financial data for some countries, we study the reduced system

$$
\begin{aligned}
\Delta v_{t}^{f, 1} & =a^{11} v_{t}^{f, 1}+b^{1}+\varepsilon_{t}^{1} \\
\Delta v_{t}^{f, 2} & =b^{2}+\varepsilon_{t}^{2} \\
\Delta v_{t}^{f, 3} & =a^{33} v_{t}^{f, 3}+a^{37} g_{t}+b^{3}+\varepsilon_{t}^{3} \\
\Delta v_{t}^{m, 1} & =a^{44} v_{t}^{m, 1}+b^{4}+\varepsilon_{t}^{4} \\
\Delta v_{t}^{m, 2} & =b^{5}+\varepsilon_{t}^{5} \\
\Delta v_{t}^{m, 3} & =a^{66} v_{t}^{m, 3}+a^{67} g_{t}+b^{6}+\varepsilon_{t}^{6} \\
\Delta g_{t} & =b^{7}+\varepsilon_{t}^{7},
\end{aligned}
$$

where GDP is modelled as a geometric Brownian motion, as e.g. in Kruse et al. (2005). The parameters of the first six rows were estimated from the data in Section 3 for each country. Parameter estimates of the equation for GDP are given in Table 10.

Table 10: Parameter estimates, p-values and residual test statistics for the regression $\Delta g_{t}=b_{7}$

\begin{tabular}{|c|cccccc|}
\hline & AU & CAN & F & JAP & UK & US \\
\hline$b_{4}$ & 0.021 & 0.021 & 0.026 & 0.044 & 0.021 & 0.021 \\
p-values & 0.000 & 0.000 & 0.000 & 0.000 & 0.000 & 0.000 \\
\hline Serial correlation (BG) & 0.138 & 0.432 & 0.002 & 0.000 & 0.037 & 0.68 \\
Normality (JB) & 0.329 & 0.022 & 0.777 & 0.470 & 0.389 & 0.373 \\
Heteroskedasticity (GQ) & 0.559 & 0.540 & 0.956 & 0.998 & 0.536 & 0.965 \\
\hline ADF t-statistic & -6.249 & -5.895 & -3.188 & -2.859 & -6.41 & -5.457 \\
p-value & $i 0.01$ & $i 0.01$ & $i 0.01$ & $i 0.01$ & $i 0.01$ & $i 0.01$ \\
KPSS level & 0.065 & 0.166 & 1.455 & 1.876 & 0.034 & 0.050 \\
p-value & $i 0.1$ & $i 0.1$ & $i 0.1$ & $i 0.1$ & $i 0.1$ & $i 0.1$ \\
\hline
\end{tabular}

Notes. See Table 2 for description of the test statistics. 


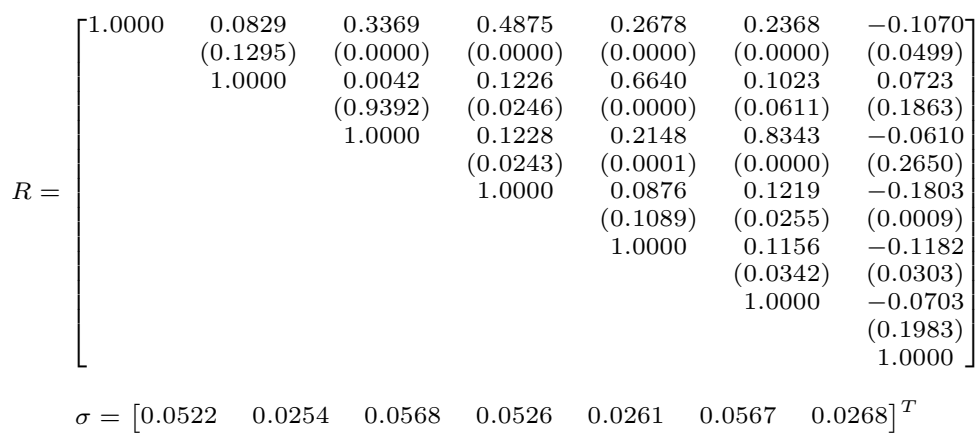

The results are in general in line with those for US. However, in contrast with the US data, the residuals of $\Delta v_{t}^{f, 1}$ are now correlated with $\Delta v_{t}^{m, 3}$, but not with $\Delta v_{t}^{f, 2}$. Symmetrically, the same applies to $\Delta v_{t}^{m, 1}$ and $\Delta v_{t}^{f, 3}$. Also, on a global level, the residuals for male and female $\Delta v^{1}$ and male $\Delta v^{2}$ are negatively correlated with the residuals of $\Delta g_{t}$, with low p-values, whereas this no longer applies to $\Delta v^{3}$. Recall, however, that the equation for $\Delta g_{t}$ is now different from the one used in the US model where interest rate spreads appeared as regressors.

\section{Simulations}

We study the behaviour of the developed model for the US by generating 10000 simulations 50 years into the future, starting from the observed values of the risk factors at the end of year 2006.

\subsection{Historical parameter estimates}

In the first set of simulations, parameters of the model were estmated from the historical US data of 1953-2006, with the exception of standard deviations of $v^{1}, v^{2}$ and $v^{3}$, which were estimated from the global data, in order to get a more comprehensive view on the uncertainty involved in the future development of mortality.

Figures 10 and 11 display sample paths and confidence intervals, respectively, for all the nine risk factors. Figure 12 plots the median and the 95\%-confidence interval for yearly survival probabilities in the final year of simulation as a function of age. Figure 13 displays the development of the median and the 95\%-confidence interval for the survival index of the cohort aged 50 in the year 2006 .

Figure 14 plots the level sets of an estimated two-dimensional kernel density of the values of the survival index of a female reference cohort aged 50 in the year 2006, and log-GDP at the end of the 50-year simulation period. The shape of the probability density illustrates the long-range dependency between GDP and mortality in the older age groups. In the simulated scenarios where the mortality of the elderly improves rapidly, also GDP has grown faster.

In general, the simulation results appear reasonable except perhaps for the fast increase in $v^{3}$ and the corresponding annual survival probabilities for males. This is reflected in the development of the survival indices in Figure 13 where males would appear to outlive females in the long run, an outcome that may be questioned. Another questionable feature of the estimated model is the 
indefinite growth of $v^{2}$. The growth is well supported by historical data but it seems unlikely that the growth rate would remain the same when $v^{2}$ reaches the levels of $v^{1}$.
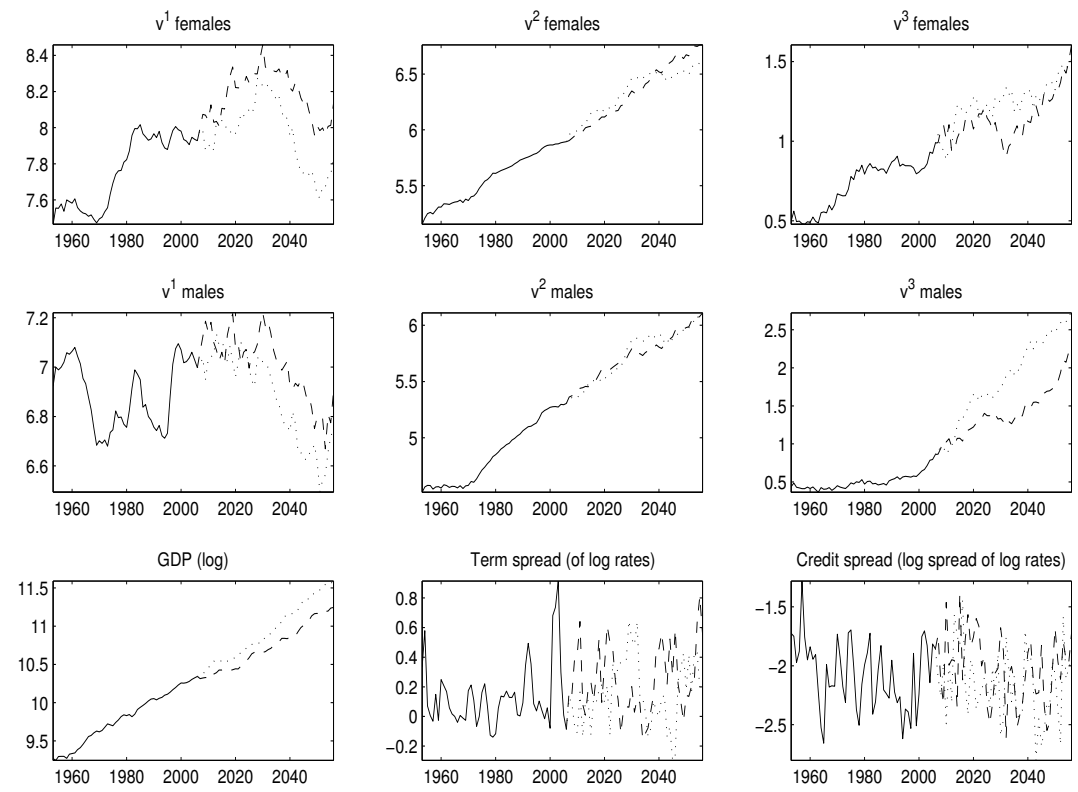

Figure 10: Two sample paths of the risk factors.

\subsection{Subjective modifications}

Due to its simple structure and the natural interpretation of its parameters, the developed model is easy to modify according to the views of the user. For example, if one believes that the period of rapid growth $v^{3}$ in the 2000s does not provide correct description of its future development, one may choose to use parameters $a^{66}$ and $a^{67}$ estimated from the truncated period of 1950-2000. It is also straightforward to add dependencies between the mortality risk factors. If we believe that the future development of $v^{2}$ depends on $v^{1}$, we can include $v^{1}$ and in the drift terms of $v^{2}$. In the following simulations, we replace the equations for $v^{f, 2}$ and $v^{m, 2}$ with

$$
\Delta v_{t}^{f, 2}=b^{2} \tanh \left(c^{f}\left(v_{t-1}^{f, 1}-v_{t-1}^{f, 2}\right)\right),
$$

and

$$
\Delta v_{t}^{m, 2}=b^{5} \tanh \left(c^{m}\left(v_{t-1}^{m, 1}-v_{t-1}^{m, 2}\right)\right),
$$

where $b^{2}$ and $b^{5}$ are as before, and $c^{f}$ and $c^{m}$ are positive constants. As $v^{2}$ approaches $v^{1}$, the drift of $v^{2}$ goes to zero before $v^{2}$ overtakes $v^{1}$. We choose $c^{f}=\frac{3}{2}$ and $c^{m}=2$, so that when the differences between $v^{1}$ and $v^{2}$ are at their current levels (approximately 2 for females and 1.5 for males), the value of the hyperbolic tangent function is approximately one, and $v^{2}$ grows like a drifting Brownian motion. Such adjustments are, of course, highly subjective, and reflect the views of the user. 

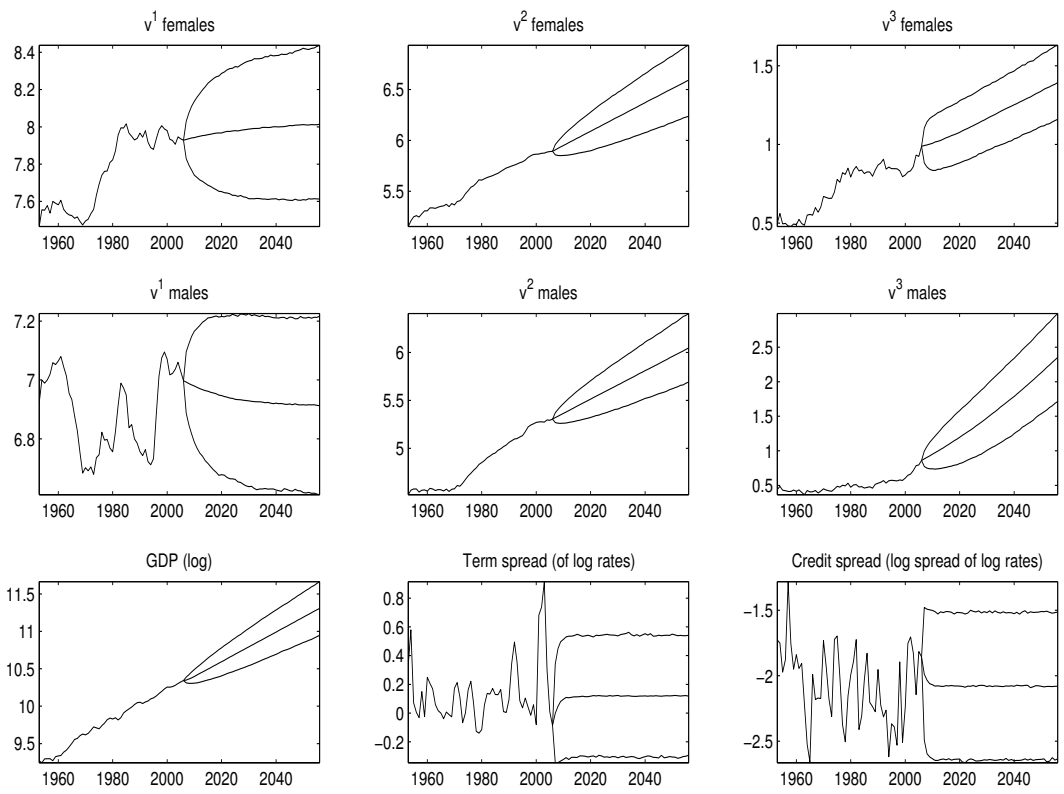

Figure 11: Development of the medians and 95\% confidence intervals of the risk factors.
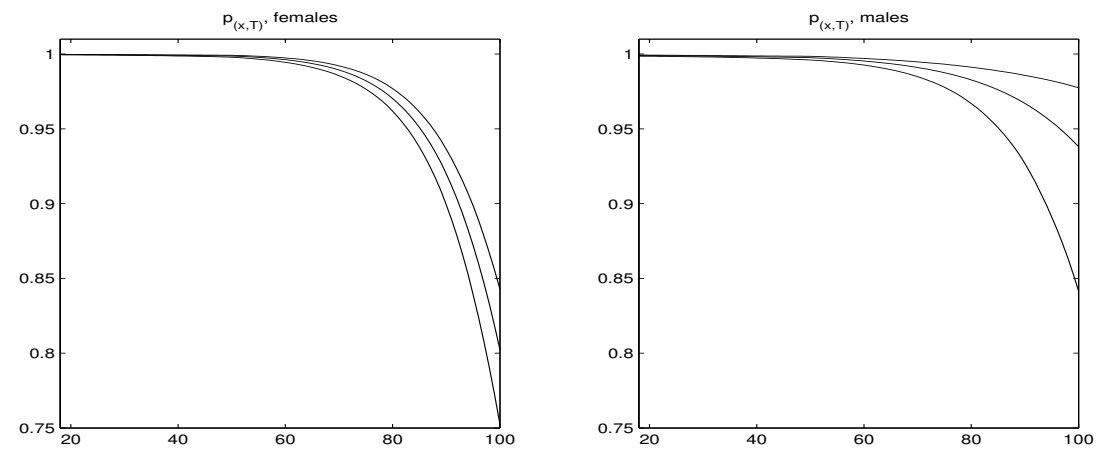

Figure 12: Median and 99\% confidence interval for yearly survival probability in year 2056 as a function on age.

In the following, we rerun the simulations with aforementioned adjustments. We simulate for a longer period of 100 years, so that the dependency of $v^{2}$ on $v^{1}$ is better demonstrated. Results are presented in Figures 15, 16 and 17. As expected, the increase in $v^{2}$ begins to slow down as it gets closer to $v^{2}$. The development of survival probabilities and indices is now better in accordance with the common view that women tend to outlive men. Also, the mortality improvement of males is now more moderate than in the previous model. Whether this is a better description of the future development of mortality is again a matter of subjective opinion. 

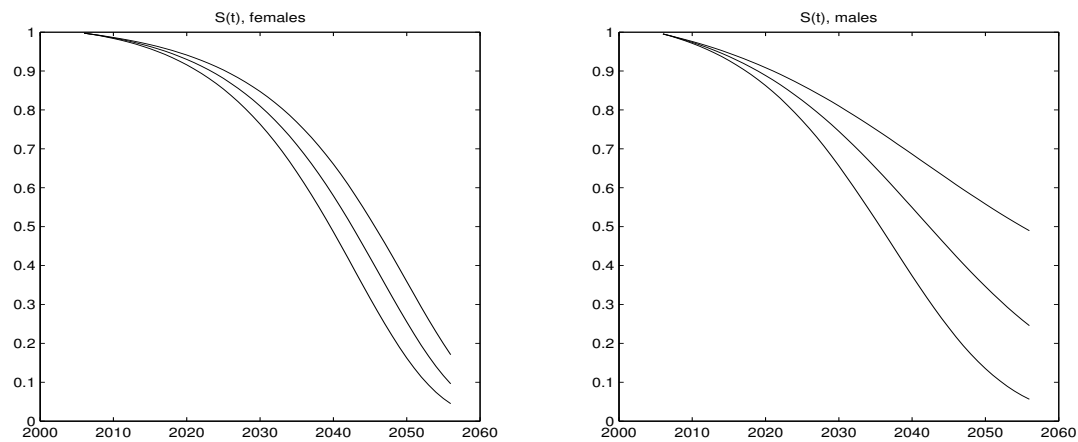

Figure 13: Development of the median and $99 \%$ confidence interval for survival index as a function of time for the cohort aged 50 in year 2006 .

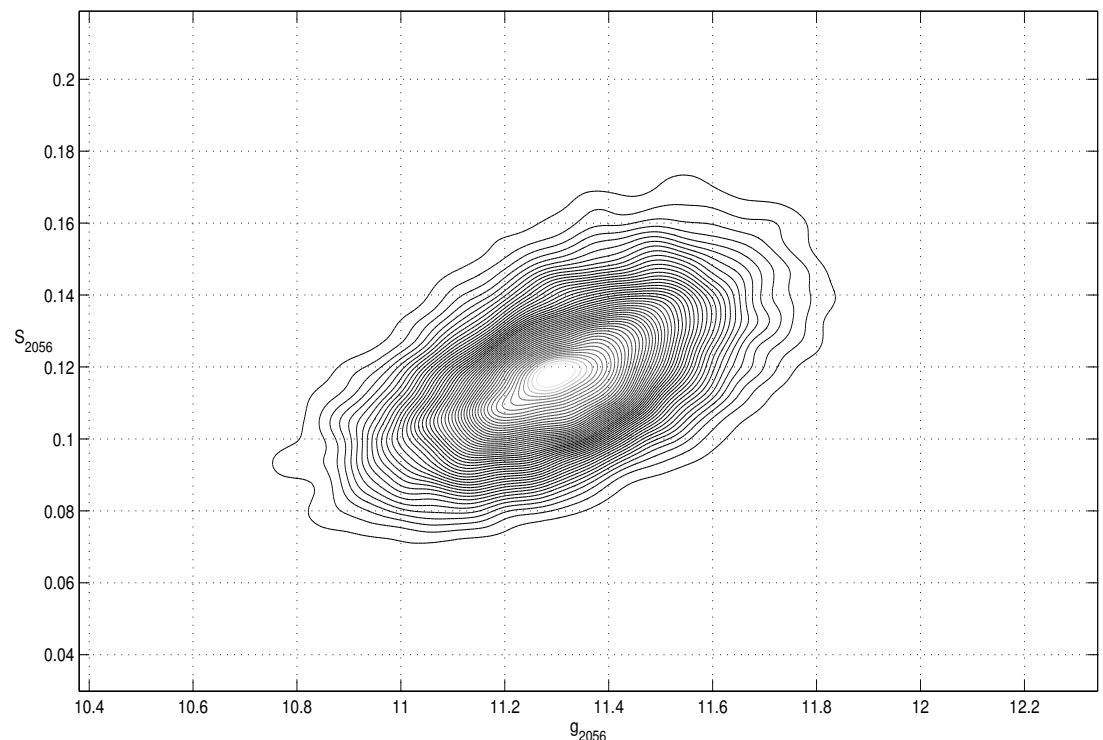

Figure 14: Kernel density estimate of the joint distribution of the survival index $S_{2056}$ of a reference cohort of females aged 50 in year 2006 and $\log$ GDP $g_{2056}$ in the year 2056

\section{Conclusions}

This paper proposes simple stochastic models for the joint development of mortality and financial markets. Particular emphasis was placed on the long-term patterns in mortality, and their connections with the economy. Due to its simple structure, the model is easy to calibrate to historical data and to user's views concerning the future development of mortality and financial markets. Including additional risk factors, such as other financial variables, would also be straightforward. 

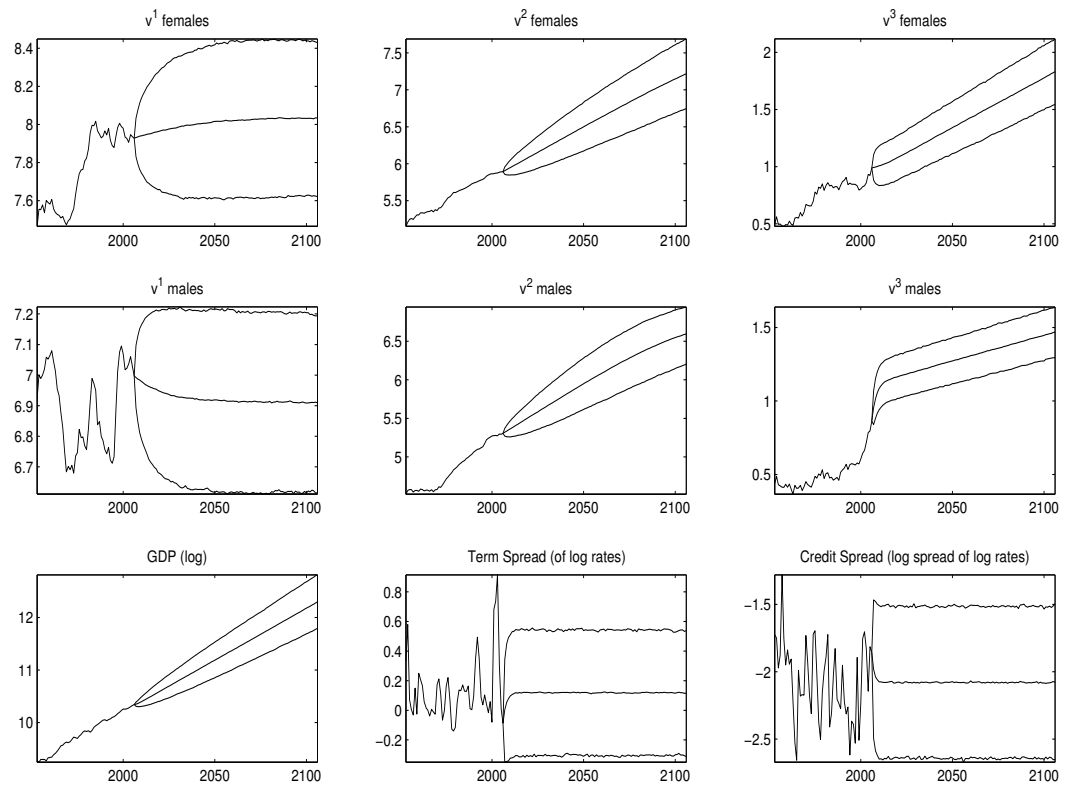

Figure 15: Development of the medians and $95 \%$ confidence intervals of the risk factors.
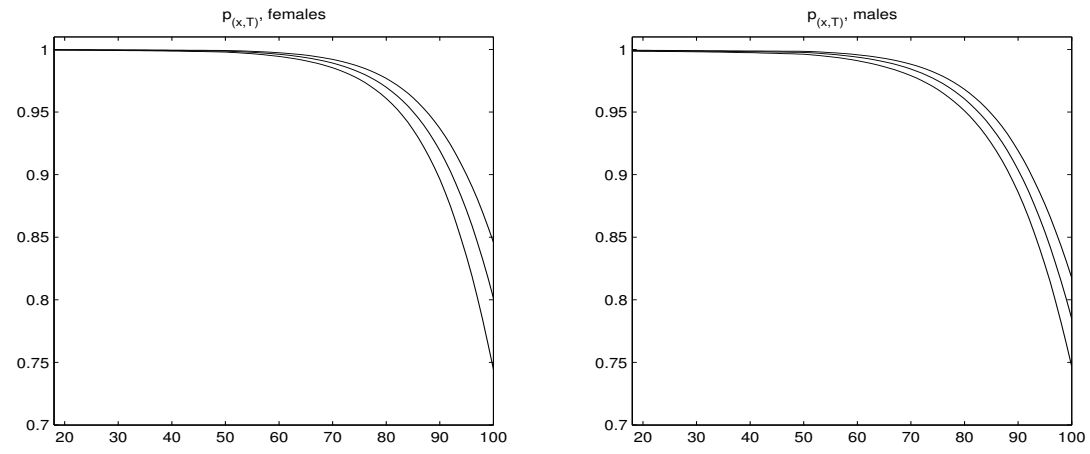

Figure 16: Median and 99\% confidence interval for yearly survival probability in year 2056 as a function on age, after parameter adjustments for $v_{2}$ and $v_{3}$.

Based on statistical analysis of an extensive data set, we found both long and short-term dependencies between mortality risk factors and GDP. The long-term dependence shows in the regression equations, while the short-term connections appear in correlation structure of the residuals. We also provide corroboration for the relation of GDP to bond markets. The proposed models incorporate these features in simple systems of linear stochastic difference equations. The models are easy to simulate and to adjust according to user's views.

The development of the models was motivated by their potential use in pricing and hedging of mortality-linked financial instruments such as longevity 

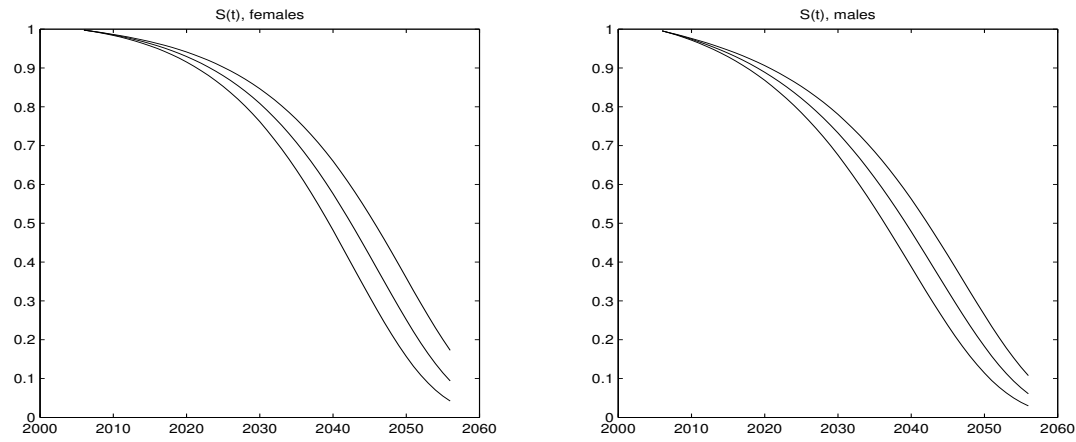

Figure 17: Development of the median and $99 \%$ confidence interval for survival index as a function of time for the cohort aged 50 in year 2006, after parameter adjustments for $v_{2}$ and $v_{3}$.

bonds, forwards and swaps. These new instruments have been found to be valuable risk management tools e.g. for pension insurers; see Cairns (2011); Blake et al. (2006b); Coughlan et al. (2011); Li and Luo (To appear). The emerging market for these new products would benefit from the development of hedging strategies that would allow the seller of a mortality-linked instrument to reduce his mortality exposure by appropriate trading in assets for which liquid markets already exist. The established connections between mortality and bond yields suggest that this might be achievable to some extent by appropriate trading in fixed-income markets. This is a nontrivial problem and it will be studied in a separate article.

\section{References}

S. Allender, P. Scarborough, M. O'Flaherty, and S. Capewell. Patterns of coronary heart disease mortality over the 20th century in England and Wales: Possible plateaus in the rate of decline. BMC Public Health, 8(1):148, 2008.

Helena Aro and Teemu Pennanen. A user-friendly approach to stochastic mortality modelling. European Actuarial Journal, 1:151-167, 2011. ISSN 21909733 .

P. Barrieu, H. Bensusan, N. El Karoui, C. Hillairet, S. Loisel, C. Ravanelli, and Y. Salhi. Understanding, modelling and managing longevity risk: key issues and main challenges. Scandinavian Actuarial Journal, to appear.

R. J. Barro. The stock market and investment. The Review of Financial Studies, 3(1):pp. 115-131, 1990.

B. S. Bernanke. On the Predictive Power of Interest Rates and Interest Rate Spreads. SSRN eLibrary, 1990.

E. Biffis and D. Blake. Mortality-linked securities and derivatives. Pensions Institute Discussion Paper, PI 0901, 2009. 
D. Blake, A. J. G. Cairns, and K. Dowd. Living with mortality: Longevity bonds and other mortality-linked securities. British Actuarial Journal, 12: 153-197(45), 2006a.

David Blake and William Burrows. Survivor bonds: Helping to hedge mortality risk. The Journal of Risk and Insurance, 68(2):pp. 339-348, 2001. ISSN 00224367 . URL http://www.jstor.org/stable/2678106.

David Blake, Andrew Cairns, Kevin Dowd, and Richard MacMinn. Longevity bonds: Financial engineering, valuation, and hedging. The Journal of Risk and Insurance, 73(4):pp. 647-672, 2006b.

H. Booth, J. Maindonald, and L. Smith. Applying Lee-Carter under conditions of variable mortality decline. Population Studies, 56(3):325-336, 2002.

B. Bosworth, S. Hymans, and F. Modigliani. The stock market and the economy. Brookings Papers on Economic Activity, 1975(2):pp. 257-300, 1975.

N. Brouhns, M. Denuit, and J. Vermunt. A Poisson log-bilinear regression approach to the construction of projected lifetables. Insurance: Mathematics and Economics, 31(3):373-393, December 2002.

A. Cairns and T. Kleinow. Mortality and smoking prevalence: An empirical investigation in ten developed countries. Manuscript, 2011.

A. J.G. Cairns. Modelling and management of longevity risk: approximations to survival functions and dynamic hedging. Insurance: Mathematics and Economics, 49, 2011.

A.J. G. Cairns, D. Blake, and K. Dowd. A two-factor model for stochastic mortality with parameter uncertainty: Theory and calibration. Journal of Risk $\&$ Insurance, 73(4):687-718, 2006.

A.J.G. Cairns, D. Blake, K. Dowd, G. D. Coughlan, D. Epstein, A. Ong, and I Balevich. A quantitative comparison of stochastic mortality models using data from England and Wales and the United States. Pensions Institute Discussion Paper, PI 0701, 2007.

A.J.G. Cairns, D. Blake, and K. Dowd. Modelling and management of mortality risk: a review. Scandinavian Actuarial Journal, 2-3:79-113, 2008.

Rebel A. Cole, Fariborz Moshirian, and Qiongbing Wu. Bank stock returns and economic growth. Journal of Banking $\mathscr{E}$ Finance, 32(6):995 - 1007, 2008.

Guy D. Coughlan, Marwa Khalaf-Allah, Yijing Ye, Sumit Kumar, Andrew J.G. Cairns, David Blake, and Kevin Dowd. Longevity hedging 101: A framework for longevity basis risk analysis and hedge effectiveness. North American Actuarial Journal, 15, 2011.

David M. Cutler, Angus S. Deaton, and Adriana Lleras-Muney. The determinants of mortality. Working Paper 11963, National Bureau of Economic Research, January 2006. 
E Philip Davis and Gabriel Fagan. Are financial spreads useful indicators of future inflation and output growth in EU countries? Journal of Applied Econometrics, 12(6):701-14, Nov.-Dec. 1997.

Stefano DellaVigna and Joshua M. Pollet. Demographics and industry returns. The American Economic Review, 97(5):pp. 1667-1702, 2007.

Richard Doll, Richard Peto, Jillian Boreham, and Isabelle Sutherland. Mortality in relation to smoking: 50 years' observations on male British doctors. BMJ, 328(7455):1519, 2004.

K. Dowd, D. Blake, A.J.G Cairns, and P. Dawson. Survivor swaps. The Journal of Risk and Insurance, 73(1):1-17, 2006.

Darrell Duffie and Kenneth Singleton. Credit Risk: Pricing, Measurement and Management. Princeton University Press, Princeton, N.J., 2003.

Arturo Estrella and Gikas A. Hardouvelis. The term structure as a predictor of real economic activity. The Journal of Finance, 46(2):pp. 555-576, 1991.

Arturo Estrella and Frederic S. Mishkin. Predicting U.S. recessions: Financial variables as leading indicators. The Review of Economics and Statistics, 80 (1):pp. 45-61, 1998.

Stanley Fischer and Robert C. Merton. Macroeconomics and finance: The role of the stock market. NBER Working Papers 1291, National Bureau of Economic Research, Inc, April 1985.

Earl S. Ford, Umed A. Ajani, Janet B. Croft, Julia A. Critchley, Darwin R. Labarthe, Thomas E. Kottke, Wayne H. Giles, and Simon Capewell. Explaining the decrease in U.S. deaths from coronary disease, 1980?2000. New England Journal of Medicine, 356(23):2388-2398, 2007.

Federal Reserve Bank of St. Louis: 1-Year Treasury Constant Maturity Rate (GS1); U.S. Department of Labor: Bureau of Labor Statistics FRED Federal Reserve Economic Data. http://research.stlouisfed.org/fred2/ series/GS1?cid=115, 2011a.

Federal Reserve Bank of St. Louis: 5-Year Treasury Constant Maturity Rate (GS5); U.S. Department of Labor: Bureau of Labor Statistics FRED Federal Reserve Economic Data. http://research.stlouisfed.org/fred2/ series/GS5?cid=115, 2011b.

Federal Reserve Bank of St. Louis: Moody's Seasoned Aaa Corporate Bond Yield (AAA); U.S. Department of Labor: Bureau of Labor Statistics FRED Federal Reserve Economic Data. http://research.stlouisfed.org/ fred2/series/AAA?cid=119, 2011c.

Federal Reserve Bank of St. Louis: Moody's Seasoned Baa Corporate Bond Yield (BAA); U.S. Department of Labor: Bureau of Labor Statistics FRED Federal Reserve Economic Data. http://research.stlouisfed.org/ fred2/series/BAA?cid=119, 2011d.

Benjamin M. Friedman and Kenneth N. Kuttner. Money, income, prices, and interest rates. The American Economic Review, 82(3):pp. 472-492, 1992. 
James D. Hamilton. Time series analysis. Princeton University Press, Princeton, N.J., 1994.

K. Hanewald. Explaining mortality dynamics: The role of macroeconomic fluctuations and cause of death trends. North American Actuarial Journal, 15 (2), 2011b.

Katja Hanewald, Thomas Post, and Helmut Grndl. Stochastic mortality, macroeconomic risks, and life insurer solvency. The Geneva Papers on Risk and Insurance - Issues and Practice, forthcoming, 2011a.

Campbell R. Harvey. The real term structure and consumption growth. Journal of Financial Economics, 22(2):305 - 333, 1988.

Campbell R. Harvey. Forecasts of economic growth from the bond and stock markets. Financial Analysts Journal, 45(5):38, 1989.

Joseph G. Haubrich and Ann M. Dombrosky. Predicting real growth using the yield curve. Economic Review (00130281), 32(1):26, 1996.

Jessica Y. Ho and Samuel H. Preston. US mortality in an international context: Age variations. Population and Development Review, 36(4):749-773, 2010.

Vaino Kannisto, Jens Lauritsen, A. Roger Thatcher, and James W. Vaupel. Reductions in mortality at advanced ages: Several decades of evidence from 27 countries. Population and Development Review, 20(4):pp. 793-810, 1994.

Susanne Kruse, Matthias Meitner, and Michael Schrder. On the pricing of GDPlinked financial products. Applied Financial Economics, 15(16):1125 - 1133, 2005 .

R.. Lee and L. Carter. Modeling and forecasting U.S. mortality. Journal of the American Statistical Association, 87(419):659-671, 1992.

R. Lee and T. Miller. Evaluating the performance of the Lee-Carter method for forecasting mortality. Demography, 38(4):537-549, 2001.

David A Leon. Trends in European life expectancy: a salutary view. International Journal of Epidemiology, 40(2):271-277, 2011.

J.S.-H. Li and M.R. Hardy. Measuring basis risk in longevity hedges. North American Actuarial Journal, 15, 2011.

J.S.-H. Li and A. Luo. Key q-duration: A framework for hedging longevity risk. ASTIN Bulletin, To appear.

Y. Lin and S. H. Cox. Securitization of mortality risks in life annuities. The Journal of Risk and Insurance, 72(2):227-252, 2005.

Maddison. http://www.ggdc.net/MADDISON/oriindex.htm, 2011.

France Mesl and Jacques Vallin. Diverging trends in female old-age mortality: The United States and the Netherlands versus France and Japan. Population and Development Review, 32(1):pp. 123-145, 2006. 
Wesley C. Mitchell and Arthur F. Burns. Statistical indicators of cyclical revivals. NBER Bulletin, 69, 1938.

National Vital Statistics. Deaths: leading causes for 2006. National Vital Statistics Report, 58(14), 2010.

S. Jay Olshansky, Douglas J. Passaro, Ronald C. Hershow, Jennifer Layden, Bruce A. Carnes, Jacob Brody, Leonard Hayflick, Robert N. Butler, David B. Allison, and David S. Ludwig. A potential decline in life expectancy in the united states in the 21st century. N Engl J Med, 352(11):1138-1145, 2005.

Charles I. Plosser and K. Geert Rouwenhorst. International term structures and real economic growth. Journal of Monetary Economics, 33(1):133 - 155, 1994.

James M. Poterba. Demographic structure and asset returns. Review of Economics and Statistics, 83(4):565-584, 2001.

Samuel H. Preston. The changing relation between mortality and level of economic development. Population Studies, 29(2):pp. 231-248, 1975.

Samuel H Preston. The changing relation between mortality and level of economic development. International Journal of Epidemiology, 36(3):484-490, 2007.

Samuel H. Preston and Haidong Wang. Sex mortality differences in the United States: The role of cohort smoking patterns. Demography, 43(4):pp. 631-646, 2006 .

Roland Rau, Eugeny Soroko, Domantas Jasilionis, and James W. Vaupel. Continued reductions in mortality at advanced ages. Population and Development Review, 34(4):747-768, 2008.

A. E. Renshaw and S. Haberman. Lee-Carter mortality forecasting with agespecific enhancement. Insurance: Mathematics and Economics, 33(2):255272, October 2003.

G. B. Rodgers. Income and inequality as determinants of mortality: An international cross-section analysis. Population Studies, 33(2):pp. 343-351, 1979.

Christopher J. Ruhm. Are recessions good for your health? Quarterly Journal of Economics, 115(2):617-650, 2000.

Myron S. Scholes. Derivatives in a dynamic environment. The American Economic Review, 88(3):pp. 350-370, 1998. ISSN 00028282.

S.A. Schroeder. We can do better - improving the health of the American people. New England Journal of Medicine, 357:1221-1228, 2007.

G William Schwert. Tests for unit roots: A Monte Carlo investigation. Journal of Business 83 Economic Statistics, 7(2):147-59, April 1989.

James H. Stock and Mark W. Watson. Forecasting output and inflation: The role of asset prices. Journal of Economic Literature, 41:788-829(42), 2003. 
Jose A Tapia Granados. Increasing mortality during the expansions of the US economy, 1900-1996. International Journal of Epidemiology, 34(6):1194-1202, 2005a.

Jos A Tapia Granados. Recessions and mortality in spain, 1980-1997. European Journal of Population/Revue europenne de Dmographie, 21:393-422, 2005b.

A. R. Thatcher. The long-term pattern of adult mortality and the highest attained age. Journal of the Royal Statistical Society. Series A (Statistics in Society), 162(1):pp. 5-43, 1999.

I Vaartjes, M O'Flaherty, D E Grobbee, M L Bots, and S Capewell. Coronary heart disease mortality trends in the Netherlands 1972-2007. Heart, 97(7): 569-573, 2011.

Jacques Vallin and France Mesl. Convergences and divergences in mortality. Demographic Research Special Collections, 2(2):11-44, 2004.

Oldrich Vasicek. An equilibrium characterization of the term structure. Journal of Financial Economics, 5(2):177 - 188, 1977.

David Wheelock and Mark Wohar. Can the term spread predict output growth and recessions? A survey of the literature. Review, Sep:419-440, 2009.

S. D. Wicksell. Sveriges framtida befolkning under olika frutsttningar. Ekonomisk Tidskrift, 28:91-123, 1926. 